\title{
HOUSE DESIGN VARIABLES IN PROVIDING INDOOR THERMAL COMFORT IN WARM HUMID CLIMATE
}

\section{Laina Hilma Sari*/**, Zahriah*}

*) Department of Architecture, Syiah Kuala University, Banda Aceh, Indonesia

**) Center for thermal, vibration and acoustic applies studies, Syiah Kuala University, Banda Aceh, Indonesia

e-mail: laina_hilma@unsyiah.ac.id

\begin{abstract}
Housing design in warm-humid tropics is widely studied using various ways. In the climate, achieving low inside air temperature is challenged by high relative humidity for providing comfort. Therefore, this study aims at finding multiple ways in house design to achieve naturally indoor thermal comfort. In this case, house design variables were analyzed by using TAS (Thermal Analysis Software) building simulation software as well as supported by literature reviews. The simulations carried out some variables of dwelling design to identify the best approach to obtain low indoor thermal performance. In this study, the objective is to achieve the low inside air temperature by taking the weather data of Banda Aceh as the case study in TAS simulation. In this article, the house design variables discussed are building materials, shape, ventilation, house orientation, shading, and environmental indications.
\end{abstract}

Keywords: house design variables, tropics, TAS soft ware

\section{INTRODUCTION}

Building thermal comfort in tropics is a pretty huge issue which is affected by the use of construction materials on various house design. Indonesia is positioned in a warm- humid climate. Therefore, the building construction should be assigned with the proper building materials considering the environment. Without adequate consideration, the indoor thermal performance might no longer meet the thermal relief standard. Concerning this issue, this article studied the influence of some building constructing variables to meet indoor thermal comfort requirements in a warm-humid zone.

By taking Banda Aceh as the case, the simulation utilized the building materials frequently used in Banda Aceh. The weather information applied in the simulation is the weather data of Banda, which was measured with the aid of the 
local meteorology office on the 5th and sixth of June 2019. However, the solar radiation data, including global and diffuse, is no longer accessible from the meteorology office. Therefore, TAS simulated the data from CIBSE Guide A. Banda Aceh, which is warm humid, has excessive outdoor air temperature within the day, yet cozy all through the night time and in the early morning. It also has excessive relative humidity, which, therefore, the passive strategy is an excellent alternative to cool down the layout. In this study, the result of the simulation is evaluated via the ability of house design variables in presenting the lower peak interior temperature, which is just as lovely as the night time value.

\section{THEORY / RESEARCH METHODS}

The study performed the data through a quantitative approach, which mixed the building simulation and literature review. The building simulation utilized was TAS (Thermal Analysis Software), which has dynamic simulation as an essential approach. TAS tracks down the thermal performance of the building through a collection of the hourly photograph. It gives a designated thermal performance of the building, not solely below severe plan conditions, but also during a regular year.

TAS simulation approves the effect of the thermal procedures on buildings, timing, areas, and interactions, to be precisely calculated (TAS EDSL, 2011). While the literature evaluations adopted in this study are the methods of thermal comfort in building designs that support the simulation results

\section{RESULTS AND DISCUSSION}

The results are directly discussed through the parameter of shapes, sun orientation, ventilation and shadings, building materials, insulations, and environmental factors. TAS considered the validation process, which results in about 1 to $20 \mathrm{C}$ different from reality. The annual indoor thermal performance was affected to obtain PMV (Predicted Mean Vote) value by applying the metabolic rate, i.e., 1,2 met and external work, i.e., $0 \mathrm{~W} / \mathrm{m} 2$. The values represent the light activities, and light clothing applied to the users.

\section{Shape}

In this case, we simulated some parameters such as floor area, facade design, and roof shape. We found that a full floor vicinity can minimize the interior air temperature. It can be approached by designing fewer interior partitions or interior walls. Such a strategy additionally permits the air to go with the flow at some point in the residence sketch and, as a result, limit the internal air temperature. TAS simulated that amongst the ground region of $2 \mathrm{~m} 2,3 \mathrm{~m} 2$ and $5 \mathrm{~m} 2$, the $5 \mathrm{~m} 2$ is in a position to have the inner air temperature $0,2 \mathrm{~K}$ cooler than the narrowest one. We can see this design, such as in usual Japanese houses, which follow the open-plan layout with giant windows for circulating air motion across rooms (Iwashita et al., 
1998). The homes in Thailand also apply such designs for cooling down the inner air temperature (Tantasavasdi et al., 2001).

In the case of shape, the following varieties, i.e., circle, rectangular, have no considerable impacts in decreasing the inside air temperature. Instead, TAS indicated that minimizing the surface toward sun radiation is more extensive to mitigate the internal air temperature

For roof design, TAS simulated that a flat roof two has a terrible overall performance due to the presence of the excessive air temperature. While pitch roofs are advocated for being applied in warm-humid areas. However, figure 1 shows that the gable roof works better in imparting the decrease internal air temperature compared with the other pitch roofs (figure 1).

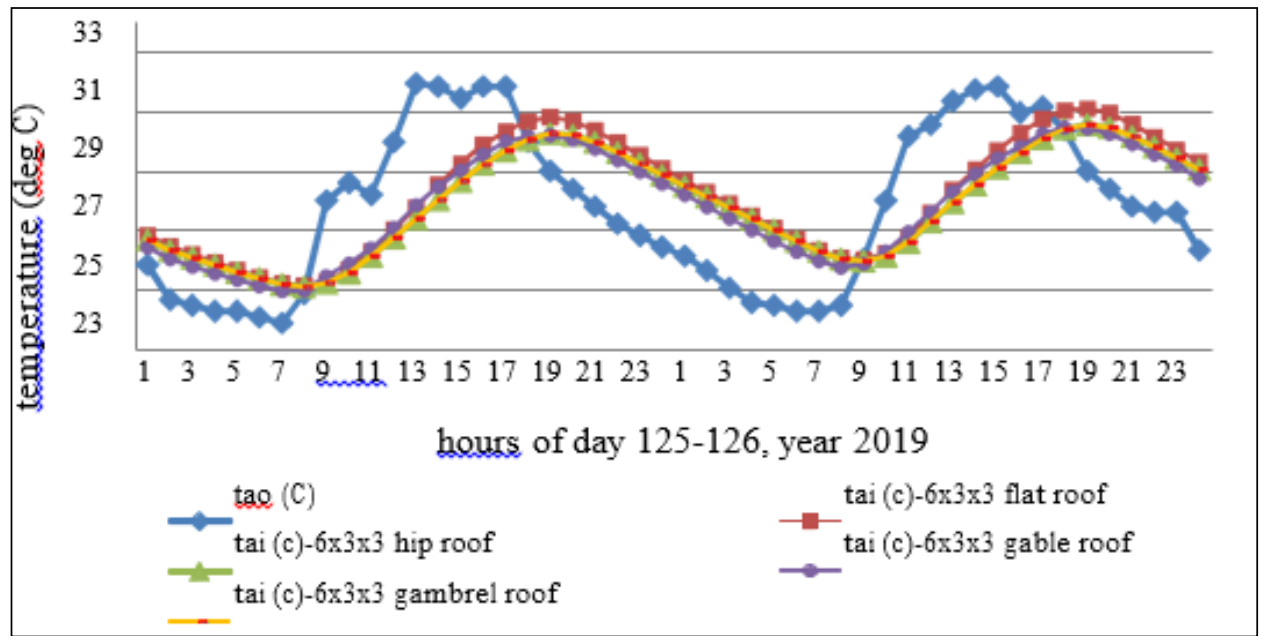

Figure 1. The Roof Shape Variations in Performing Inside Air Temperature

House types also work in cooling down the internal air temperature. TAS simulated that grounded house works well in cooling down the interior air temperature. In contrast, the raised ground house can increase the internal air temperature due to the fact the outdoor floor of the raised ground is not directly heated convectively via the excessive outside air temperature. Stilt residence is frequent for a usual home in tropics, which aims at sheltering the houses from floods and wild animal attacks. The local people also experience such design for the excellent thermal relief provision, which is a distinction to what TAS calculated. The thermal remedy through the stilt house can also come from the light constructing materials, shadings, and apertures, which are pretty integral in tropics. Openings are utilized both on the wall and on the stilt floor. The floor has some light leakages along the board floor for circulating the air across the building to reduce the interior air temperature. Many traditional houses also apply the stilt house, such as Malaysian houses (Tahir et al., 2010) and Acehnese house (Sari et al. 2016). 


\section{Sun orientation}

Good house design should consider the sun orientation. TAS simulated the various direction of building toward the sun orientation. This study found that the northern and southern adjustment of the house openings would decrease the air temperature due to the absence of direct sun radiation during the day. Meanwhile, the north-eastern and north-western orientations perform the slightly higher inside air temperature. In contrast, the eastern and western direction of the openings give the highest value of the inside air temperature

\section{Ceiling size and Shading}

To achieve the low inside air temperature buildings with apertures in the tropics, we also should consider the higher ceiling. TAS simulated that the higher the roof the lower the electricity use because the vertical temperature gradients are smaller once the zone is occupied. Hashimoto (2009) found in his study that a higher ceiling will also allow the increased airflow, consequently permitting the room to meet the thermal relief level.

The apertures, such as the window provision are good-sized in reducing the interior air temperature. TAS simulated that each massive and mild building substances with home windows are capable of minimizing the air temperature up to $2 \mathrm{~K}$ from the structures besides home windows (figure 2).

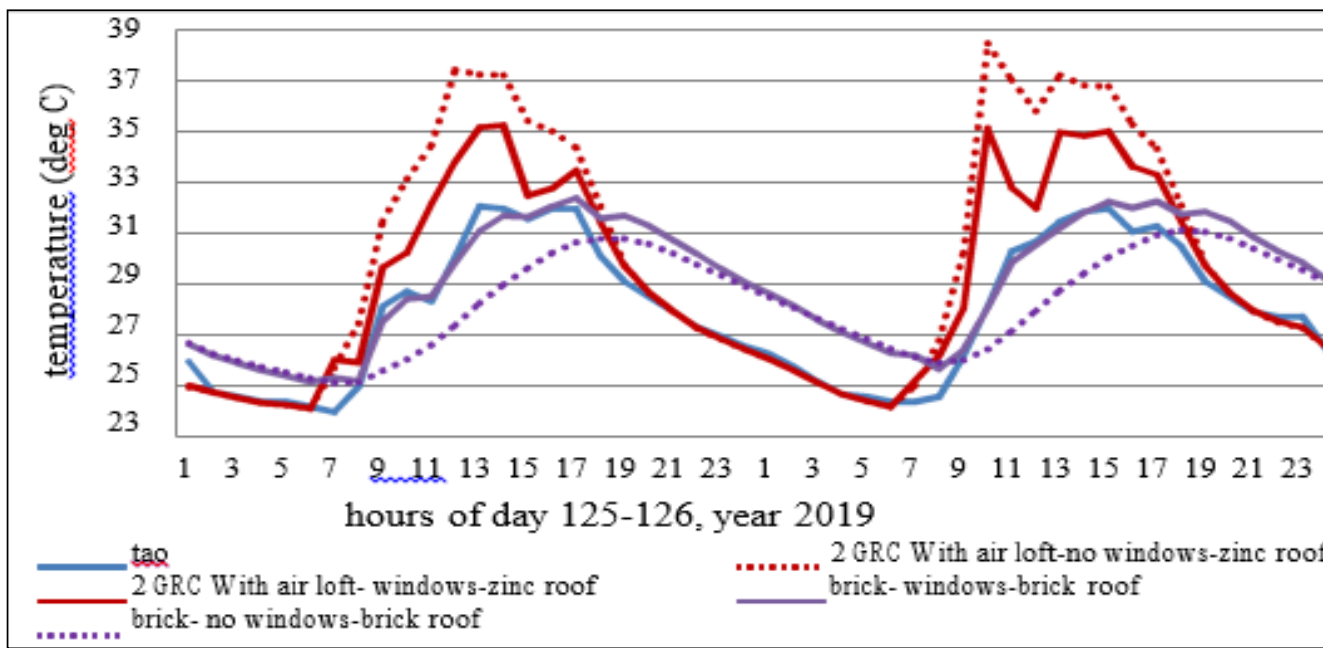

Figure 2. Heavy and Light Building Materials Designed with/out Windows in Reducing Inside Air Temperature

In the hotter climate, airflow plays a crucial function in decreasing the inner air temperature. TAS simulations indicated that large apertures would contribute to the extreme indoor thermal performance because of solar penetration. Therefore, 
there are quite a few approaches to utilize the airflow effectively to minimize the interior air temperature:

a. Location of the apertures to the windward. TAS performs that higher Wind speed; the lower air temperature can be (figure 3). The openings, such as windows and any other ventilation, can induce the windward that would decrease the electricity use in cooling down the building (Kammerud et al., 1984).

b. Sufficient openings to catch the available wind. TAS calculated that higher wind speeds could lower the air temperatures (figure 3). Windows and other vents will produce a higher level of efficiency that can save energy for shelter (Kammerud et. Al., 1984). Based on tentative calculations for building models, the rising load increased by $35 \%$ due to the increase in air changes rising from 3.3 to 17 per hour in warmer increments.

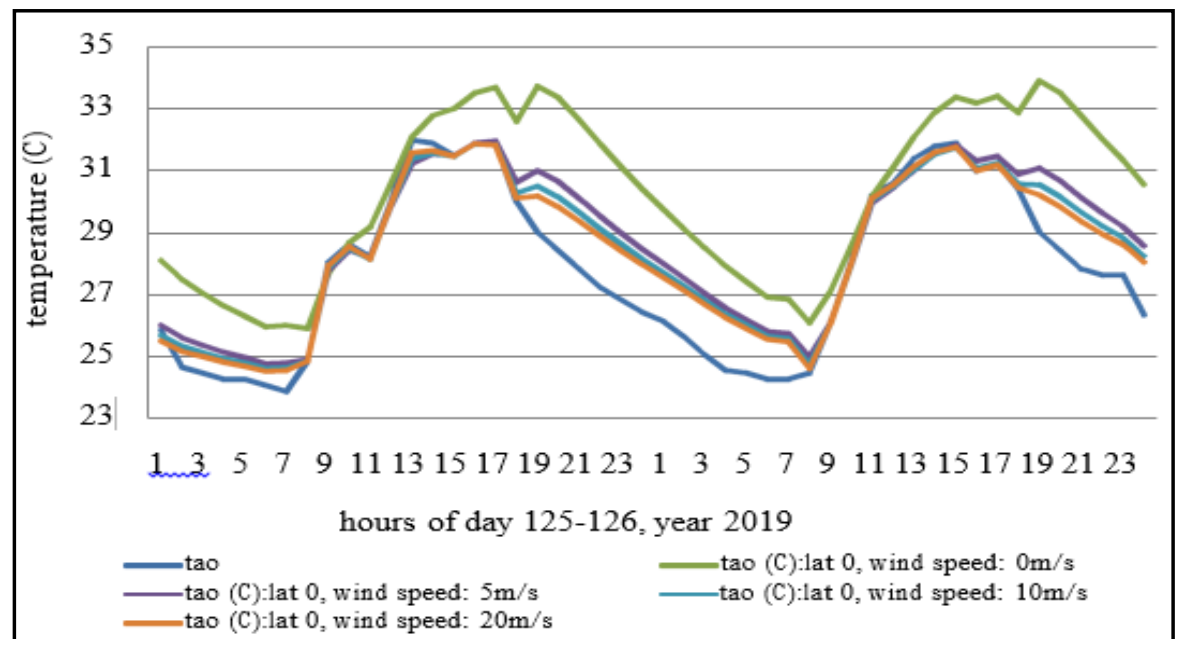

Figure 3. The relation of Airspeed and The Air Temperature

c. Design more shadings in the opening area. Providing shadings on the walls and above the openings can avoid the unnecessary heat transfer into the house. The use of a balcony in housing design works well as the shading tool. The shaded area can increase air velocity and increase the level of comfort in the room during the metabolic rate of 1.25 met such as standing. While during sitting activities, the thermal performance is rated as slightly cold (Prianto et. Al., 2002). Designing large apertures such as a window without consideration of orientation and use of the shade will make the closer inside air temperature to the outside value. Even worse with the use of incompatible wall materials which will increase the air temperature value. The aperture such as windows must be appropriately arranged to circulate the air. Windows should also be shaded to prevent the transmission of heat. 
d. Use the configuration window to reach low indoor temperatures. The window configuration would also provide indoor thermal comfort. A $45^{0}$ tilted pivot window can induce the airspeed which contributes thermal comfort. For warmhumid climate, a window with a downward position tilted in $>45^{0}$ works effectively in circulating the air into the room. The use of blind angles from $60^{\circ}$ to $90^{\circ} \mathrm{can}$ meet a comfort level for the activity of 1.25 met (Prianto et. al, 2002)

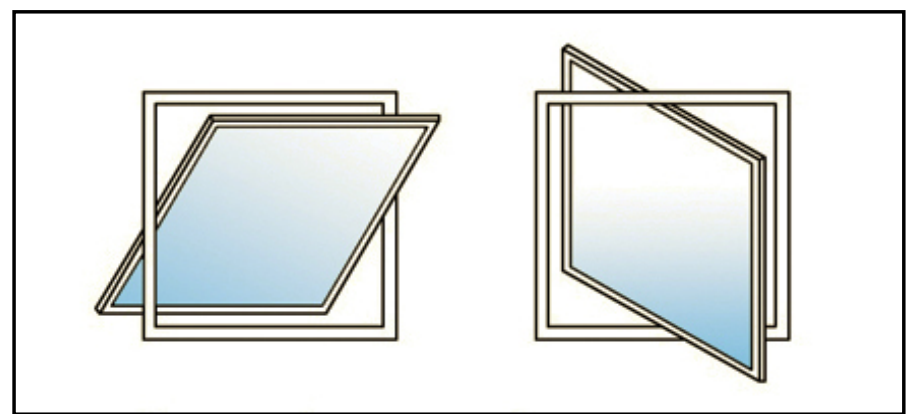

Figure 4. Pivot Windows

\section{Building Materials}

In tropics, light-weight materials are suggested by many kinds of literature for being applied in the wall structure. TAS additionally calculates that light-weight weight construction will decrease the thermal sensation dissatisfaction. This might also be because of the lower value of inside air temperature drawing near the external value delivered by the night time and early morning. However, light-weight wall building in some cases will furnish a high inside air temperature, which can be $6 \mathrm{~K}$ higher than the peak value of the outdoor air temperature. Therefore, the use of light-weight substances should not be positioned directly on solar orientation which could contribute high radiation or to be completely shaded.

Nowadays, many people in Indonesia prefer to have heavy-weight wall construction applied in their residence design. TAS indicates that this construction system will decrease the peak value of the outside air temperature by $1 \mathrm{~K}$ all through the day. This is also the reason why most residence developers constructed the housing in such a manner, apart from the greater inflexible and robust performance. However, during the night, heavy-weight structure with their thermal mass will create a higher air temperature compared with the outside air temperature. It can be the reason why the resider frequently utilizes air conditioners during evening and night till the following morning. This condition can be sorted out by utilizing a natural night cooling device and designing shades to minimize the exposure of the wall to the sun.

In tropical areas, cement and ceramic tile are typically applied as the floor materials. These materials also work effectively as the cooling floor which can reduce the inside air temperature by $0.2 \mathrm{~K}$. For the roof, lightweight with low conductivity value material decreases the internal air temperature. A long time ago, 
sago leaf was used to be the roof material in Acehnese traditional dwelling. But nowadays the clay and metal roofs are commonly applied. In this case, TAS simulated some roof materials which then prove that thatch or leaf is the most pleasant roof material in reducing the air temperature compared with clay tile, metallic, and brick roof (figure 5).

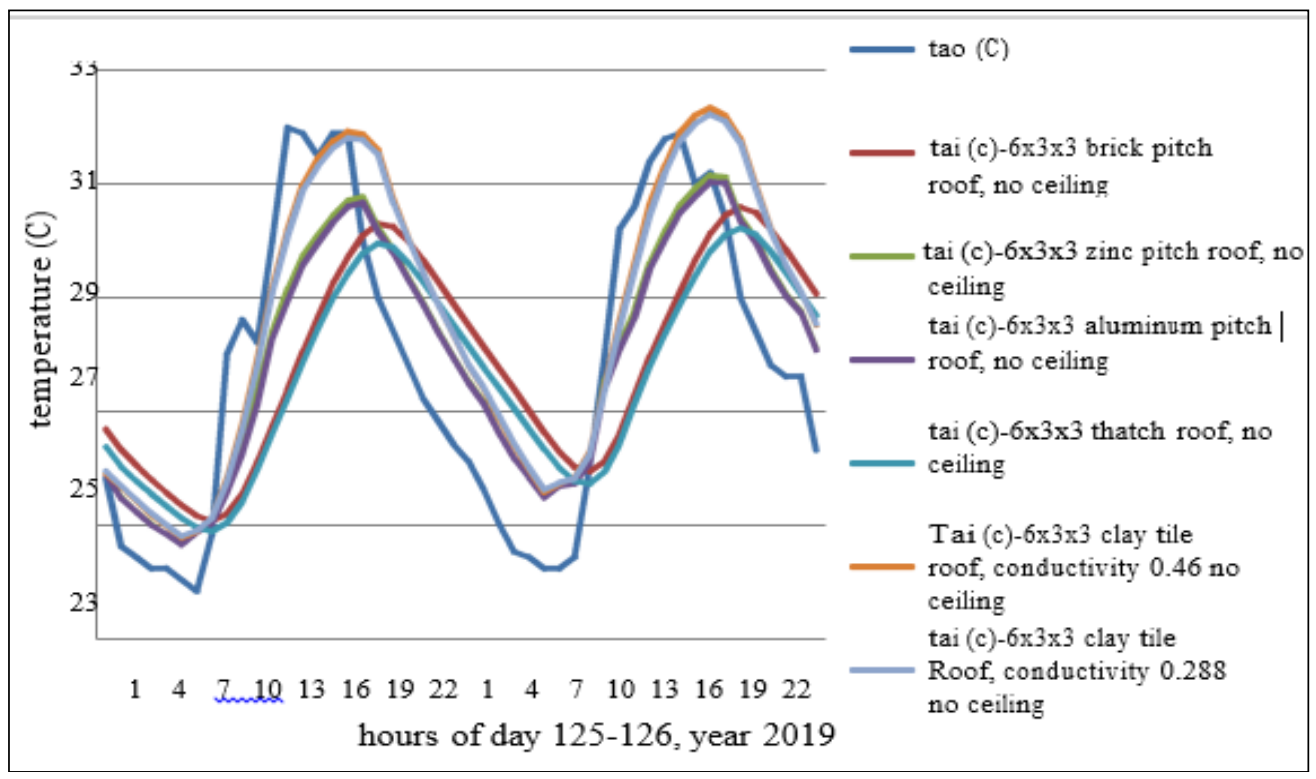

Figure 5. Influence of Roof Materials upon Inside Air Temperature

To create a cooling surface material in topics, we should consider the material with the high reflectance value and in contrast the low absorptance value so that absorbed warmth is radiated again to the sky. White plaster effectively achieves this combination. In the field, some housings in Aceh are designed with aluminum foil located between the roof and the ceiling. It is selected as the insulation because polished aluminum foil has a very high solar reflectance and low emissivity which retains heat. This is good to protect the ceiling from the naked surface metallic roof which is commonly applied in Banda Aceh. To reduce the severity of the metal roof can also be by coating the roof with light color. Another way to reduce the inside air temperature is by installing the low concentrations of mild absorbing impurities of clay or concrete such as iron oxides and elemental carbon.

In tropics, there are several ways for configuring the roof to obtain the cooling roof. Green roof both extensively or intensively is effective to cool the interior room. Many previous studies prove that green roofs are adequately regarded to work efficaciously in any climates in producing the alleviation of air temperature.

TAS indicates that roof surfaces in any colors do not show up to reduce the inside air temperature significantly. However, a mild coloration such as white could slightly reduce the air temperature compared with any dark color. Being painted on the wall, the light color would cut the temperature by $2 \mathrm{~K}$ from the wall surface 
without any paint. While in contrast, the dark color may create very excessive inner air temperatures. Coloring the roof should work effectively since the roof is a building surface heated by the sun directly. An insulated white roof can induce low thermal performance by decreasing the air temperature down to $3^{0} \mathrm{C}$ (Emmanuel, 2010). The white roof also works successfully in reducing the use of electricity in running the air condition air (Gray, 2009).

\section{Insulation}

The use of building thermal insulations in tropics is not frequently applied which is in contrast to the cold climates. However, TAS indicates that in tropics, the GRC wall insulated mineral wool board or polystyrene can decrease the temperature by $2^{0} \mathrm{C}$. Even better when it is installed below the roof, it can reduce the air temperature by way of $5.7^{\circ} \mathrm{C}$ than the outdoor air temperature. The combination use of the insulation both on the wall and under the roof would be more successful in meeting the thermal comfort.

Based on the survey, the Aluminum foil is the most frequent insulation utilized in post-disaster housing in Banda Aceh which is different from the recommended insulation proposed by TAS. It can be due to the high price and the rarely presence of mineral wool board or polystyrene in Aceh.

\section{Environmental Factors}

The microclimate, such as the surroundings, plays a significant role in creating thermal comfort (Tantasavasdi et al., 2007; Emmanuel et al., 2007). The surroundings with the contribution of the air movement through cross ventilation can reduce the indoor air temperature. The environments without sufficient greeneries can also lead to even more substantial effects such as Urban Heat Islands (UHIs).

Additionally, in tropics, extending the shading stage at a neighborhood scale will help to cool down the environments, which hence might also decrease the indoor air temperature (Emmanuel et al., 2007). The vegetation in the climate included with large bushes can reduce the air temperature considerably. In contrast, a concrete surface suffers the highest temperature (Tantasavasdi et al.,2007).

\section{CONCLUSIONS}

This article is about the study on residence design variables in performing low indoor air temperature through the use of TAS simulations on various simple models. Any relevant and supporting literature support this study. TAS simulated some cases though the analysis of shape, sun orientation, ventilation and shading, building materials, the use of insulations, and the effect of environmental factors. This study shows that besides the ability to calculate the thermal state of the case, yet TAS has some barriers. This deficiency recommends that analyzing the house 
design in performing a low indoor thermal environment should also consider previous research as well as the field measurements.

\section{ACKNOWLEDGMENT}

We acknowledge Unsyiah as the funding body of this research through Hibah Penelitian Lektor, the year 2019. We also thank Heriot University, UK for facilitating the use of TAS software and giving the knowledge to carry out this work through the advisory of Dr. Doug Harris.

\section{REFERENCES}

CIBSE A (2006) Environmental Design, The Chartered Institution of Building Services Engineers London, January 2006 (7th edition)

Cheikh, H. B., And Bouchair, A (2008), Experimental Studies of A Passive Cooling Roof in Hot Arid Areas, Revue des Energies Renouvelables Vol. 11, No 4, pp $515-522$

Emmanuel. R., Rosenlun. H., and Johansson. E (2007) Urban shading - a design option for the tropics? A study in Colombo, Sri Lanka, International Journal Of Climatology.

Emmanuel, R., (2010) Linking the 'in' and 'out:' new comfort goals for the rapidly urbanizing equatorial tropical megacities in a changing climate, Proceedings of Conference: Adapting to Change: New Thinking on Comfort, Cumberland Lodge, Windsor, UK, 9-11 April

Gray, L., (2009) Obama's green guru calls for white roofs, the Telegraph. [online]. Available from:

http://www.telegraph.co.uk/earth/earthnews/5389278/Obamas-green- guru-calls-forwhite-roofs.html

Hyde, R. A. (2000) Climatic responsive design: a study of buildings in a moderate and hot humid climate. London: E\&FN Spon Press.

Hashimoto, Y and Yoneda, H. (2009) 'Numerical Study on The Influence of A Ceiling Height for Displacement Ventilation', Eleventh International IBPSA Conference Glasgow, Scotland July 27-30, [online]. Available from: http://www.ibpsa.org/proceedings/BS2009/BS09_1045_1052.pdf

Iwashita, G. and Akasaka, H (1998) 'The effects of human behavior on natural ventilation rate and indoor air environment in summer - a field study in southern Japan', Energy and Buildings, Volume 25, Issue 3, pp. 195-205

Kammerud, R., Ceballos, B., Curtis, B., Place, W. and Anderson, B. (1984) Ventilation Cooling of Residential Buildings, ASHRAE transaction 95 (2), pp. 226-251

Live Science (2010) White Roofs Could Reduce Urban Heating, [online]. Available from: http://www.livescience.com/8069-white-roofs-reduce-urbanheating.html 
Prianto, E., \& Depecker, P. (2002) 'Characteristics of airflow as the effect of the balcony, opening design and internal division on indoor velocity: A case study of traditional dwelling in the urban living quarter in the tropical humid region'. Energy and Buildings, 34(4), pp. 401-409.

Sari, L.H, Izziah, Meutia, E, Irwansyah, M (2016), Vernacular Approach In Providing Passive Heating System For Housing In Tropical Gayo Highland, The 4th International Conference On Sustainable Built Environment "Sustainable Building And Environment For Sophisticated Life"

TAS Building Simulator theory, version 9.1, (2011). [Online]. Available From: http://www.edsl.net/main/Support/Documentation.aspx.

Tahir, M.M., Che-Ani, A.I., Abdullah, N.A.G, Tawil, N.M., Surat, M., and Ramly, A (2010) 'The Concept of Raised Floor Innovation for Terrace Housing in Tropical Climate', Journal of Surveying, Construction \& Property, Vol. 1 Issue 1

Tantasavasdi, C., Jareemit, D., Suwanchaiskul, A., and Naklada, T. (2007) 'Evaluation and Design of Natural Ventilation for Houses in Thailand', Journal of Architectural/Planning Research and Studies, Volume 5. Issue 1. Faculty of Architecture and Planning, Thammasat University. [online]. Available from: http://www.cham.co.uk/DOCS/papers/JARSEvaluationofNaturalVentilation.pdf 